\title{
Spatial Inequalities in the Incidence of Colorectal Cancer and Associated Factors in the Neighborhoods of Tehran, Iran: Bayesian Spatial Models
}

\author{
Kamyar Mansori', Masoud Solaymani-Dodaran' ${ }^{1}$, Alireza Mosavi-Jarrahi' ${ }^{2}$, Ali Ganbary Motlagh ${ }^{3}$, Masoud Salehi ${ }^{4}$, \\ Alireza Delavari ${ }^{5}$, Mohsen Asadi-Lari ${ }^{1,6}$ \\ ${ }^{1}$ Department of Epidemiology, School of Public Health, Iran University of Medical Sciences, Tehran, Iran; ${ }^{2}$ Department of Health and Community \\ Medicine, Shahid Beheshti University of Medical Sciences, Tehran, Iran; ${ }^{3}$ Department of Radiotherapy, Shahid Baheshti University of Medical \\ Sciences, Tehran, Iran; ${ }^{4}$ Department of Biostatistics, School of Public Health, Iran University of Medical Sciences, Tehran, Iran; ${ }^{5}$ Digestive Disease \\ Research Institute, Tehran University of Medical Sciences, Tehran, Iran; ${ }^{6}$ Oncopathology Research Center, Iran University of Medical Sciences, Tehran, \\ Iran
}

Objectives: The aim of this study was to determine the factors associated with the spatial distribution of the incidence of colorectal cancer (CRC) in the neighborhoods of Tehran, Iran using Bayesian spatial models.

Methods: This ecological study was implemented in Tehran on the neighborhood level. Socioeconomic variables, risk factors, and health costs were extracted from the Equity Assessment Study conducted in Tehran. The data on CRC incidence were extracted from the Iranian population-based cancer registry. The Besag-York-Mollié (BYM) model was used to identify factors associated with the spatial distribution of CRC incidence. The software programs OpenBUGS version 3.2.3, ArcGIS 10.3, and GeoDa were used for the analysis. Results: The Moran index was statistically significant for all the variables studied $(p<0.05)$. The BYM model showed that having a women head of household (median standardized incidence ratio [SIR], 1.63; 95\% confidence interval [CI], 1.06 to 2.53 ), living in a rental house (median SIR, $0.82 ; 95 \% \mathrm{Cl}, 0.71$ to 0.96 ), not consuming milk daily (median $\mathrm{SIR}, 0.71 ; 95 \% \mathrm{Cl}, 0.55$ to 0.94 ) and having greater household health expenditures (median SIR, 1.34; $95 \% \mathrm{Cl}, 1.06$ to 1.68 ) were associated with a statistically significant elevation in the SIR of CRC. The median (interquartile range) and mean (standard deviation) values of the SIR of CRC, with the inclusion of all the variables studied in the model, were 0.57 (1.01) and 1.05 (1.31), respectively.

Conclusions: Inequality was found in the spatial distribution of CRC incidence in Tehran on the neighborhood level. Paying attention to this inequality and the factors associated with it may be useful for resource allocation and developing preventive strategies in atrisk areas.

Key words: Colorectal cancer, Spatial distribution, Incidence, Neighborhood, Besag-York-Mollié (BYM) model, Tehran, Iran

Received: October 22, 2017 Accepted: December 11, 2017

Corresponding author: Mohsen Asadi-Lari, MD, PhD Department of Epidemiology, School of Public Health, Iran University of Medical Sciences, Shahid Hemmat Highway, Tehran, Iran E-mail:mohsen.asadi@yahoo.com

This is an Open Access article distributed under the terms of the Creative Commons Attribution Non-Commercial License (http://creativecommons.org/licenses/bync/4.0/) which permits unrestricted non-commercial use, distribution, and reproduction in any medium, provided the original work is properly cited.

\section{INTRODUCTION}

Colorectal cancer (CRC) is one of the most important public health problems, and it is becoming more common worldwide [1]. CRC is the third most common cancer and the fourth leading cause of death from cancer in the world, and is responsible for 8\% of all deaths from cancers. In 2012, approximately 1361000 new cases of CRC occurred, including 614000 in women and 
746000 in men [1.2]. CRC is the third most common cancer in men and the second most common cancer in women, with a standardized incidence rate of 20.6 and 14.6 per 100000 , respectively [2,3]. CRC is one of the most common cancers in Iran, where it is the third most common cancer in men and the fourth most common cancer in women, with standardized incidence rates of 8.1-8.3 and 6.5-7.5 per 100000 , respectively; moreover, CRC is responsible for $8.4 \%$ of all cancers in Iran [4-6].

In general, considerable worldwide variation exists in the incidence and mortality of CRC. Approximately $55 \%$ of cases of CRC occur in developed countries. The highest age-standardized rate (ASR) in the world has been found in Australia/New Zealand (44.8 and 32.2 per 100000 in men and women, respectively) and the lowest ASR has been reported in western Africa (4.5 and 3.8 per 100000 in men and women, respectively) [7]. Moreover, studies have shown wide variation in the incidence of CRC in different regions of Iran [8,9].

Variation in the incidence of CRC can be caused by different distributions of risk factors, especially environmental risk factors such as socioeconomic, cultural, and behavioral factors [10]. Many studies have examined the incidence of CRC in Iran and its related factors, but these studies have generally been conducted on the individual level, whereas ecological studies have deliberately been carried out on the provincial level $[11,12]$. However, the ecological fallacy states that the distribution of disease in smaller geographic units may be different from the distribution in larger units [13]. In Iran, very few studies have investigated smaller geographic units, such as neighborhoods, and the effects of socioeconomic factors and risk factors on neighborhood-level geographical inequality. Nonetheless, creating knowledge in this field (disease mapping) can be very helpful for describing the geographical variation of risk factors (hypothesis generation), identifying high-risk regions, and forming a basis for the assessment of health inequalities in order to better allocate health and medical resources $[14,15]$.

However, given the aging population and the increasing incidence of different types of cancer in Iran, especially CRC, and the importance of cancer prevention, it is necessary to identify neighborhoods with a high incidence of CRC in cities and to clarify the role of potentially relevant socioeconomic factors, health costs, and risk factors for the development of preventive strategies by using advanced statistical models. One of the most important of these advanced models is the BesagYork-Mollié (BYM) model. The BYM model has interesting fea- tures, such as being easy to interpret, having high precision, allowing the identification of geographical variations and patterns of spatial associations, and enabling the estimation of the relative weights of the risk factors for the outcome $[12,16,17]$. Therefore, based on the above considerations, the aim of this study was to determine the effect of factors (socioeconomic factors, health costs, and risk factors) associated with the spatial distribution of the incidence of CRC on the neighborhood level in Tehran (the capital of Iran) by using the BYM model.

\section{METHODS}

\section{Study Area}

This ecological study was conducted in the city of Tehran (the capital of Iran). The Tehran metropolitan area comprises $638 \mathrm{~km}^{2}$, and is situated at the latitude of $35^{\circ} 45^{\prime} \mathrm{N}$ and the longitude of $51^{\circ} 25^{\prime} \mathrm{E}$. The city has 22 districts. The geographical units of the study were 374 neighborhoods in the city of Tehran.

\section{Required Data for the Study \\ Demographic information}

In the present study, the demographic data of people aged 50 and older (the at-risk population for the incidence of CRC) were extracted from Iranian national censuses in 2006 and 2011. The population of people aged 50 and older for each neighborhood was calculated as follows:

$\frac{\text { population aged } \geq 50 \text { in the } 2006 \text { census }+ \text { population aged } \geq 50 \text { in the } 2011 \text { census }}{2}$

\section{Information regarding the incidence of colorectal cancer}

Data regarding the incidence of CRC from 2008 to 2011 were extracted from the population-based cancer registry data of the Iranian Ministry of Health and Medical Education. Then, according to the postal address of the patients, the number of CRC cases in each neighborhood was determined.

\section{Socioeconomic information, risk factors, and health expenditures}

We extracted socioeconomic variables, risk factors, and health expenditures from the Equity Assessment Study conducted in Tehran. The Equity Assessment Study was a crosssectional study conducted in Tehran in 2011 to identify inequalities in physical, psychological, social, and environmental factors. Fr data collection in 22 municipalities and neighborhoods of Tehran, multi-stage sampling was performed. Each 
district was considered independently to calculate the sample size based on the Cochrane formula, with 1535 households in each district based on variables with a prevalence of at least $10 \%$, a margin of error (d) of 0.015 , and a $95 \%$ confidence interval $(\mathrm{Cl})$. Then, to facilitate the allocation of samples to the 8-box table that had to be completed as part of the individual questionnaires and to achieve higher precision, the sample was expanded to 1600 households, regardless of the population size in each district. Then, 200 blocks were assigned to each district equally. In each block, 8 households were selected for a random systematic study. To allocate samples on the neighborhood level, the probability was proportional to the size of each district. Overall, 34700 households (118 000 individuals) were studied in 22 municipalities of Tehran in 2011. The Equity Assessment Study utilized 2 types of questionnaires, consisting of 20 parts, 14 of which were applied at the household level for all 8 selected households in the block, and 6 of which (mental health, quality of life, social capital, physical pain, oral health, and physical activity) were completed for a selected household in each block (based on the age and gender table). The details of that study were fully described by Asadi-Lari et al. [18].

\section{Statistical Analysis}

\section{The Besag-York-Mollié model}

The lack of the assumption of independent observations and overdispersion are important challenges when the Poisson model is used for count data in a spatial analysis. To deal with these challenges, hierarchical models such the BYM model have been introduced. The BYM model can be used to consider random spatial effects and/or any unstructured random effects [19]. As a hierarchical model, this model is suitable for explaining these 2 types of heterogeneity in different regions. In other words, the relative risk (RR) is divided into 3 components, as follows:

$$
\begin{gathered}
y_{i} \sim \text { Poisson }\left(E_{i} \theta_{i}\right) \\
\log \left(\theta_{i}\right)=\alpha+u_{i}+v_{i}
\end{gathered}
$$

The hierarchical approach of the BMY model is as follows:

Level 1: It is assumed that the outcomes have a Poisson distribution and that the RRs $\theta_{i}$ are independent of each other.

Level 2: The linear predictor variable assumes that $\theta_{i}$ has the following form:

$$
\log \left(\theta_{i}\right)=\alpha+u_{i}+v_{i}
$$

Where $\alpha$ is the log-RR baseline, and $v_{i}$ and $u_{i}$ represent the spatial random structure and the non-spatial random structure, respectively. Spatial autocorrelation across neighborhoods $\left(v_{i}\right)$ is induced by the conditional autoregressive (CAR) model. The CAR model represents risk factors with spatial structures, so that specific risk estimates of a given area will tend to shrink toward a local mean. The CAR model within the BYM model is as follows:

$\left\lfloor v_{i} \mid v_{j}, i \neq j, \tau_{v}^{2}\right] \sim N\left(\bar{v}_{i}, \tau_{i}^{2}\right)$ where $\bar{v}_{i}=\frac{1}{\sum_{i} w_{i j}} \sum_{j} v_{j} w_{i j}$ and $\tau_{i}^{2}=\frac{\tau_{v}^{2}}{\sum_{j} w_{i j}}$

If areas $i$ and $j$ are neighbors of each other, the weight is equal to 1 , and otherwise it is 0 .

The spatial heterogeneity model is dependent on the number of neighbors, and the assumption of independence is not always satisfied. To solve this problem, non-spatial random effects $\left(u_{i}\right)$, which usually are called exchangeable random effects, are defined. Non-spatial random effects indicate that the specific risk estimates of a given area will tend to shrink toward the global mean of the study area. This component in the BYM model is as follows:

$$
u_{i} \sim N\left(0, \tau_{u}^{2}\right)
$$

The parameters $\tau_{v}^{2}$ and $\tau_{u}^{2}$ control variability in $v$ and $u$. Level 3: On this level, the prior distribution determines the precise parameters of 2 random effects from the second level. If $G(a, b)$ represents the gamma distribution with expected value $\frac{a}{b}$ and variance $\frac{a}{b^{2}}$, for the 2 parameters of $\tau_{v}=\frac{1}{\sigma_{v}^{2}}$ and $\tau_{u}=\frac{1}{\sigma_{u}^{2}}, 2$ distributions-gamma $\left(a_{v}, b_{v}\right)$ and gamma $\left(a_{u}, b_{u}\right)$ are defined $[14,19,20]$. To select the suitable gamma distribution, we used $a_{v}=0.5$ and $b_{v}=0.005$ for spatially structured random effects and $a_{u}=0.01$ and $b_{u}=0.01$ for non-spatially structured random effects, based on previous studies in this field. These values are equivalent to a non-informative prior distribution.

\section{The inclusion of independent variables in the Besag-York- Mollié model}

The BYM model is as follows when independent variables are added:

$$
\log \theta_{i}=\alpha+u_{i}+v_{i}+\sum \beta_{i} x_{i}
$$

In this equation, $v_{i}$ and $u_{i}$ have a normal prior distribution and a normal conditional autocorrelation distribution, respectively. Additionally, $\beta$ has a prior normal distribution. 

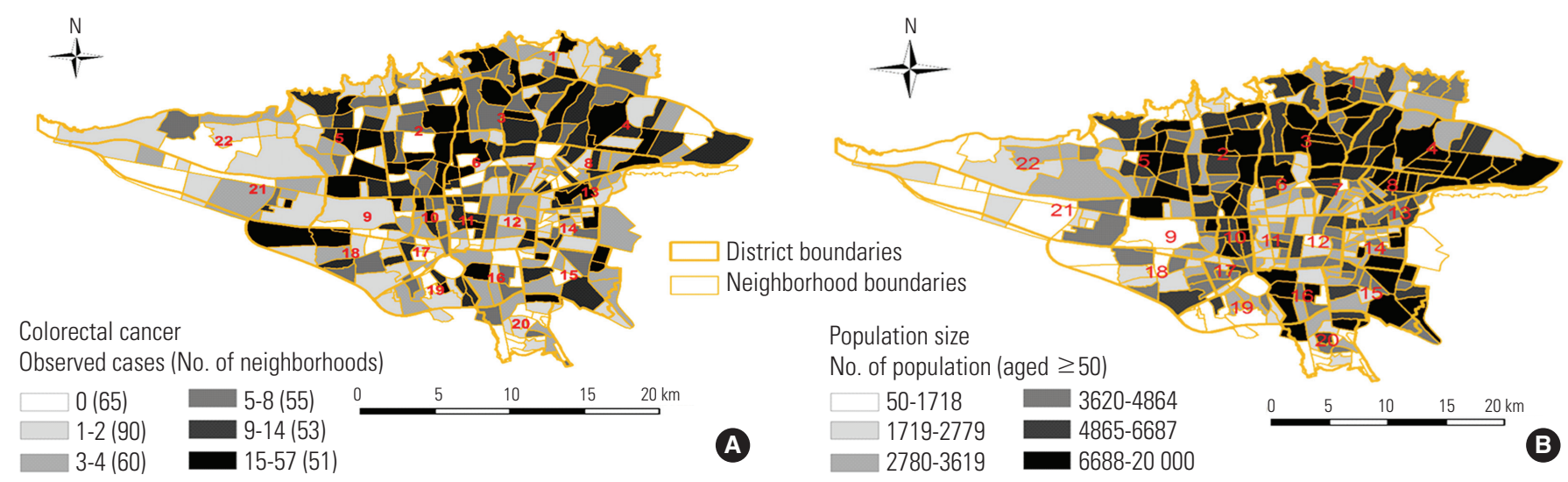

Figure 1. The number of observed cases of colorectal cancer in every neighborhood $(A)$ and the distribution of individuals $\geq 50$ years of age on the neighborhood level in Tehran (B).

\section{The Moran index}

Moran's index (MI) is known as a common statistical index for identifying spatial autocorrelation, and its values range from -1 to 1 . It is obtained from the following equation:

$$
M I=\frac{N}{\sum_{i} \sum_{j} W_{i j}} \times \frac{\sum_{i} \sum_{j} W_{i j}\left(y_{i}-\bar{y}\right)\left(y_{j}-\bar{y}\right)}{\sum_{i}\left(y_{i}-\bar{y}\right)^{2}}
$$

Where $N$ is the number of spatial units for which variable $y$ is measured and $w_{i j}$ is a spatial weight matrix defined to determine the degree of locality [21,22]. In this study, we used MI in order to identify spatial autocorrelation and justify the use of the local model (BYM model). We used a Markov-chain Monte Carlo (MCMC) simulation to estimate the model parameters. The Gibbs sampler was chosen to produce random samples through the parameter space. The convergence of the model was evaluated by Brooks-Gelman-Rubin statistics. This metric evaluates MCMC convergence by comparing the within-chain variance to the between-chain variance, and values of close to 1 indicate a high degree of convergence. We ran the MCMC model with 100000 iterations, and the first 5000 iterations were ignored as burn-in. The iterations started from overdispersed initial values on 4 parallel chains. OpenBUGS version 3.2.3 (http://www.openbugs.net/w/Downloads) was used for analysis of the BYM model.

\section{RESULTS}

A total of 2815 new cases of CRC occurred in Tehran from 2008 to 2011, of which 2491 (88.4\%) were successfully geocoded to the neighborhood level. Figure $1 \mathrm{~A}$ shows the geographical distribution of new cases of CRC at the level of neighborhoods of Tehran; as can be seen, new cases tended to be located in the northern and central areas of the city. Figure $1 \mathrm{~B}$ shows the distribution of the population aged 50 years and older on the neighborhood level between the censuses of 2006 and 2011. The fewest inhabitants were found in the neighborhoods of districts $9,18,19,21$, and 22 , which are deliberately sparsely inhabited and industrial.

Table 1 shows the mean and standard deviation (SD) and MI for all variables analyzed in the study (socioeconomic variables, health costs, and risk factors). The MI was statistically significant for all variables analyzed $(p<0.05)$. This shows that there was spatial autocorrelation at the level of the neighborhoods of Tehran for all the variables included in this study. The MI was larger for women aged 17 years or older with a university education, households living in rental houses, and households without a car.

Figure $2 \mathrm{~A}$ shows the estimated standardized incidence ratio (SIR) of CRC on the neighborhood level using the BYM model during 2008-2011. In general, the median (interquartile range) and mean (SD) values of the SIR of CRC, when there are no variables in the model, were 0.59 (1.02) and 1.06 (1.23), respectively. There was no neighborhood with a SIR of 0 , and about $32.6 \%$ of the neighborhoods had a SIR greater than 1.

Table 2 shows the associations between the variables included in the study (socioeconomic variables, risk factors, and health costs) with the SIR of CRC according to the hierarchical BYM model. As can be seen, among the variables under investigation, 4 had a significant association with the SIR of CRC: a women head of household (median SIR, 1.63; $95 \% \mathrm{Cl}, 1.06$ to 2.53), living in a rental house (median $\mathrm{SIR}, 0.82 ; 95 \% \mathrm{Cl}, 0.71$ to 0.96 ), no daily milk consumption in the household (median 


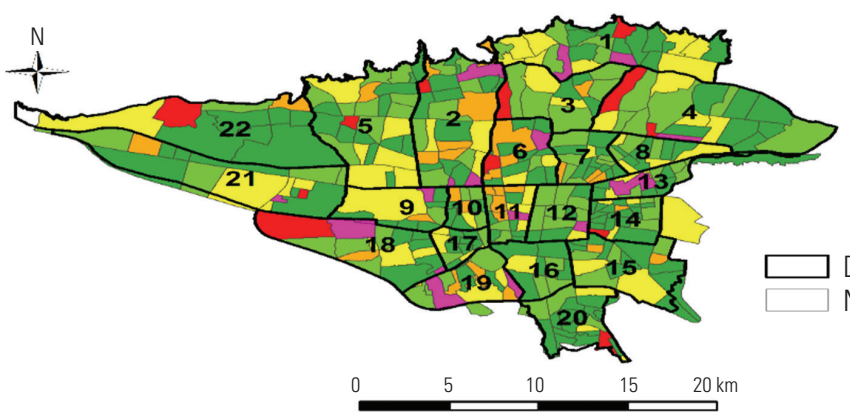

Colorectal cancer

Soothed SIR from BYM model (No. of neighborhoods)

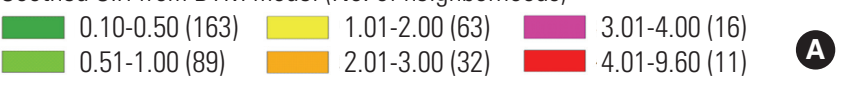

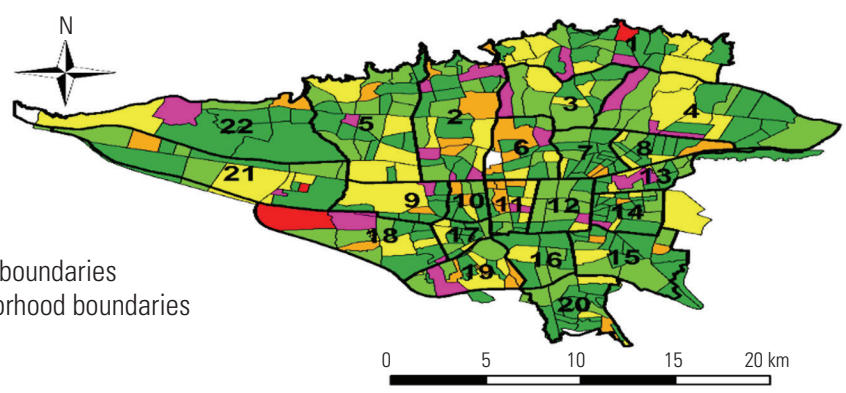

Colorectal cancer

Soothed SIR from BYM model (No. of neighborhoods)

$\begin{array}{lll}0.06-0.51(171) & \square \\ 0.52-1.00(85) & 1.01-2.00(60) & 3.01-5.00(23) \\ \square & 2.01-3.00(31) & 5.01-9.00(4)\end{array}$

Figure 2. Estimation of the standardized incidence ratios (SIRs) for each neighborhood when there are no variables in the model (A) and with the inclusion of all the variables studied in the model (B) from the Besag-York-Mollié (BYM) model.

Table 1. Mean values of variables relating to socioeconomic factors, risk factors, and health costs, along with the magnitude of the MI

\begin{tabular}{|c|c|c|c|}
\hline Variables & Mean (SD) & MI & $p$-value \\
\hline $\begin{array}{l}\text { People over } 15 \text { years old who were } \\
\text { unemployed }\end{array}$ & $9.09(1.94)$ & 0.08 & 0.01 \\
\hline $\begin{array}{l}\text { Women aged } 17 \text { years or older with a } \\
\text { university education }\end{array}$ & $30.49(13.17)$ & 0.53 & $<0.001$ \\
\hline Women head of household & $11.13(3.53)$ & 0.26 & $<0.001$ \\
\hline Households without a car & $28.96(7.64)$ & 0.47 & $<0.001$ \\
\hline Households living in a rental house & 39.34 (15.29) & 0.14 & $<0.001$ \\
\hline $\begin{array}{l}\text { Households with an income below the } \\
\text { poverty line }\end{array}$ & $19.28(14.96)$ & 0.24 & $<0.001$ \\
\hline People without insurance coverage & $28.44(12.62)$ & 0.47 & $<0.001$ \\
\hline $\begin{array}{l}\text { Households without daily fruit con- } \\
\text { sumption }\end{array}$ & $13.05(7.36)$ & 0.23 & $<0.001$ \\
\hline $\begin{array}{l}\text { Households without daily milk } \\
\text { consumption }\end{array}$ & $54.94(13.00)$ & 0.28 & $<0.001$ \\
\hline Overweight people aged 15 and older & $32.32(5.13)$ & 0.08 & 0.02 \\
\hline Smoking households & $24.11(6.20)$ & 0.14 & $<0.001$ \\
\hline Household health expenditures & $12.68(6.94)$ & 0.08 & 0.02 \\
\hline Household expenditures on diagnoses & $17.91(9.70)$ & 0.06 & 0.01 \\
\hline Household expenditures on medicine & $45.86(14.03)$ & 0.07 & 0.02 \\
\hline Household expenditures on hospitals & $9.67(9.85)$ & 0.17 & $<0.001$ \\
\hline $\begin{array}{l}\text { Household expenditures on medical } \\
\text { visits }\end{array}$ & $18.17(8.35)$ & 0.07 & 0.03 \\
\hline
\end{tabular}

MI, Moran index; SD, standard deviation.

SIR, $0.71 ; 95 \% \mathrm{Cl}, 0.55$ to 0.94 ), and higher household health expenditures (median SIR, 1.34; 95\% Cl, 1.06 to 1.68). For example, every $10 \%$ increase in having a women head of household and in household health expenditures led to a $63 \%$ and $34 \%$ increase in the SIR of CRC, respectively.

Figure $2 \mathrm{~B}$ shows the SIRs of $C R C$ at the neighborhood level
Table 2. Associations of socioeconomic variables, risk factors, and health costs with the incidence of CRC by the BYM model

\begin{tabular}{|c|c|c|}
\hline Variables & Median SIR & $95 \% \mathrm{Cl}$ \\
\hline $\begin{array}{l}\text { People over } 15 \text { years old who were } \\
\text { unemployed }\end{array}$ & 1.17 & $0.63,2.19$ \\
\hline $\begin{array}{l}\text { Women aged } 17 \text { years or older with a } \\
\text { university education }\end{array}$ & 0.91 & $0.77,1.06$ \\
\hline Women head of household & 1.63 & $1.06,2.53$ \\
\hline Households without a car & 0.88 & $0.73,1.08$ \\
\hline Households living in a rental house & 0.82 & $0.71,0.96$ \\
\hline $\begin{array}{l}\text { Households with an income below the } \\
\text { poverty line }\end{array}$ & 1.13 & $0.90,1.40$ \\
\hline People without insurance coverage & 1.05 & $0.90,1.11$ \\
\hline Households without daily fruit consumption & 1.02 & $0.92,1.14$ \\
\hline Households without daily milk consumption & 0.71 & $0.55,0.94$ \\
\hline Overweight people aged 15 and older & 0.95 & $0.78,1.17$ \\
\hline Smoking households & 0.95 & $0.85,1.07$ \\
\hline Household health expenditures & 1.34 & $1.06,1.68$ \\
\hline Household expenditures on diagnoses & 1.01 & $0.87,1.18$ \\
\hline Household expenditures on medicine & 1.05 & $0.94,1.18$ \\
\hline Household expenditures on hospitals & 1.15 & $0.98,1.35$ \\
\hline Household expenditures on medical visits & 1.12 & $0.95,1.32$ \\
\hline
\end{tabular}

CRC, colorectal cancer; BYM, Besag-York-Mollié; SIR, standardized incidence ratio; $\mathrm{Cl}$, confidence interval.

in Tehran based on the BYM model, with all the socioeconomic variables, risk factors, and health costs entered into the BYM model for each neighborhood. As can be seen, the highest SIRs of CRC occurred in neighborhoods located in the northern and central regions of Tehran. Overall, the median (interquartile range) SIR of CRC was 0.57 (1.01), and $31.5 \%$ of the neighborhoods had an SIR greater than 1. Additionally, the mean (SD) SIR of CRC was 1.05 (1.31) based on the BYM model. 


\section{DISCUSSION}

In the present study, the highest SIRs of CRC were found in neighborhoods that were located in the northern and central regions of Tehran. The people living in these areas generally have a higher socioeconomic status, have completed higher levels of education, pay more attention to their health, and undergo more screening tests. Therefore, more cases of cancer are diagnosed in them [23]. Additionally, CRC incidence may also be associated with lifestyle factors such as physical activity and diet, because people residing in urban areas, especially regions with a relatively high economic status, usually have less mobility and consume more fast food, both of which increase the SIR of CRC $[7,24]$. Additionally, supporting the above conclusions, the present study showed a statistically significant association between high household health expenditures (median SIR, 1.34; 95\% Cl, 1.06 to 1.68) and the SIR of CRC. This finding could reflect a tendency for households that pay more attention to their health to participate more in diagnostic and screening programs of cancer, meaning that more cases of CRC will be diagnosed in them. However, these diagnosed cases are more likely to be in the early stages of the disease and have a better prognosis [25-28].

A statistically significant association was found between having a women head of household (median SIR, 1.63; $95 \% \mathrm{Cl}$, 1.06 to 2.53 ) and the SIR of CRC. This is one of the most important indicators of socioeconomic status that is directly related to poverty. Households with a women head of household usually do not have a favorable socioeconomic status. Because of legal and cultural factors, they generally do not have the capability to provide for living expenses and emerge from poverty [28]. This finding is consistent with most studies that have been carried out in this field. For example, Karamifar et al. [29] found that the incidence of CRC was higher in people who had completed low levels of formal education and who lived in neighborhoods with lower socioeconomic status. In another study by Aarts et al. [30], individuals with a low socioeconomic status had a higher risk for CRC in the US and Canada, but this risk was lower in Europe. Kim et al. [31] also showed that living in neighborhoods with a high socioeconomic status and education levels may be a protective factor against CRC. In general, low socioeconomic status is an important risk factor for the development of several types of cancer. People with a lower socioeconomic status have less access to health care and diagnostic tests, and are also less likely to participate in screening programs due to an inability to pay the required fees; as a result, fewer cases of cancer may be reported in them. The cases that are diagnosed are more likely to be in the final stages and do not have a good prognosis [32,33]. Additionally, people with a lower socioeconomic status are more susceptible to several types of diseases for various reasons. For example, diet is an important factor for gastrointestinal cancers; people in lower socioeconomic strata are more likely not to consume a healthy diet that contains fiber and fruit, and may therefore have a higher risk of cancer.

In this study, living in a rental house (median SIR, 0.82; 95\% $\mathrm{Cl}, 0.71$ to 0.96 ) was inversely associated with the SIR of CRC. Renters usually belong to lower socioeconomic strata, with the corresponding implications for cancer risk.

An inverse statistical association was found between the absence of daily milk consumption and the SIR of CRC (median $\mathrm{SIR}, 0.71 ; 95 \% \mathrm{Cl}, 0.55$ to 0.94$)$. This result is not consistent with most studies in this field. The meta-analysis conducted by Aune et al. [34] showed that milk and dairy products, with the exception of cheese, were associated with reduced CRC risk. A study conducted by Green et al. [35] showed that milk intake did not have a significant association with the risk of CRC. A study by Baena and Salinas [36] also found that milk intake of $525 \mathrm{~mL} / \mathrm{d}$ was associated with a $26 \%$ risk reduction of CRC in men. In general, the protective effect of milk is mediated by calcium, because milk is a rich source of calcium. Perhaps the most important reason for this problem is the ecological falla$c y$, because in our research, the unit studied was the neighborhood $[37,38]$. This fallacy can also affect variables such as the lack of fruit consumption and overweight, which in the present study did not show a significant association with the SIR of CRC.

This study had a number of limitations and strengths. One of the strengths of this study is that it is the first ecological study in Iran to examines the simultaneous effect of various socioeconomic factors, health costs, and risk factors on the SIR of CRC on the neighborhood level using the BYM model. Its limitations include the ecological fallacy, which makes it impossible to speak with certainty about the results. Another issue that may affect the results is the edge effect, which refers to the fact that border neighborhoods can be affected by the size of adjacent regions. A further limitation is that the geocoding of CRC cases in some neighborhoods may have been accompanied by a certain degree of misclassification due to incomplete postal addresses. 
In conclusion, all the variables analyzed in this study showed spatial autocorrelations at the level of the neighborhoods of Tehran. The results of the BYM model also showed that having a women head of household, living in a rental house, not consuming milk daily, and high household health expenditures had a statistically significant association with the SIR of CRC. In general, this study showed that inequality was present in the spatial distribution of the incidence of CRC on the neighborhood level in Tehran. Paying attention to this inequality and associated factors will be useful for resource allocation and the development of preventive strategies in at-risk areas.

\section{ACKNOWLEDGEMENTS}

This article was extracted from Kamyar Mansori's $\mathrm{PhD}$ thesis in the Department of Epidemiology, School of Public Health, Iran University of Medical Sciences. We would like to express our sincere gratitude to the staff of the cancer office of Iran's Ministry of Health and Medical Education for providing the data.

\section{CONFLICT OF INTEREST}

The authors have no conflicts of interest associated with the material presented in this paper.

\section{ORCID}

Kamyar Mansori http://orcid.org/0000-0001-5008-8547

Masoud Solaymani-Dodaran https://orcid.org/0000-00021817-5664

Alireza Mosavi-Jarrahi https://orcid.org/0000-0001-80439221

Ali Ganbary Motlagh https://orcid.org/0000-0002-75966016

Masoud Salehi https://orcid.org/0000-0002-4939-4675

Alireza Delavari https://orcid.org/0000-0002-0111-200X

Mohsen Asadi-Lari http://orcid.org/0000-0003-3390-7154

\section{REFERENCES}

1. Shah SA, Neoh HM, Rahim SS, Azhar ZI, Hassan MR, Safian N, et al. Spatial analysis of colorectal cancer cases in Kuala Lumpur. Asian Pac J Cancer Prev 2014;15(3):1149-1154.

2. Ferlay J, Soerjomataram I, Dikshit R, Eser S, Mathers C, Rebelo
$M$, et al. Cancer incidence and mortality worldwide: sources, methods and major patterns in GLOBOCAN 2012. Int J Cancer 2015;136(5):E359-E386.

3. Rafiemanesh H, Pakzad R, Abedi M, Kor Y, Moludi J, Towhidi F, et al. Colorectal cancer in Iran: epidemiology and morphology trends. EXCLI J 2016;15:738-744.

4. Moghimi-Dehkordi B, Safaee A, Zali MR. Prognostic factors in 1,138 Iranian colorectal cancer patients. Int J Colorectal Dis 2008;23(7):683-688.

5. Kolahdoozan S, Sadjadi A, Radmard AR, Khademi H. Five common cancers in Iran. Arch Iran Med 2010;13(2):143-146.

6. Mohagheghi MA, Mosavi-Jarrahi A, Malekzadeh R, Parkin M. Cancer incidence in Tehran metropolis: the first report from the Tehran Population-based Cancer Registry, 1998-2001. Arch Iran Med 2009;12(1):15-23.

7. International Agency for Research on Cancer. GLOBOCAN 2012: estimated cancer incidence, mortality and prevalence worldwide in 2012 [cited 2018 Jan 15]. Available from: http://globocan.iarc.fr/Default.aspx.

8. Khosravi Shadmani F, Ayubi E, Khazaei S, Sani M, Mansouri Hanis S, Khazaei S, et al. Geographic distribution of the incidence of colorectal cancer in Iran: a population-based study. Epidemiol Health 2017;39:e2017020.

9. Ansari R, Mahdavinia M, Sadjadi A, Nouraie M, Kamangar F, Bishehsari $F$, et al. Incidence and age distribution of colorectal cancer in Iran: results of a population-based cancer registry. Cancer Lett 2006;240(1):143-147.

10. Johnson CM, Wei C, Ensor JE, Smolenski DJ, Amos Cl, Levin B, et al. Meta-analyses of colorectal cancer risk factors. Cancer Causes Control 2013;24(6):1207-1222.

11. Chamanparaa P, Moghimbeigi A, Faradmal J, Poorolajal J. Exploring the spatial patterns of three prevalent cancer latent risk factors in Iran; using a shared component model. Int J Epidemiol Res 2015;2(2):68-77.

12. Mahaki B, Mehrabi Y, Kavousi A, Akbari ME, Waldhoer T, Schmid VJ, et al. Multivariate disease mapping of seven prevalent cancers in Iran using a shared component model. Asian Pac J Cancer Prev 2011;12(9):2353-2358.

13. Piantadosi S, Byar DP, Green SB. The ecological fallacy. Am J Epidemiol 1988;127(5):893-904.

14. Andrew B, Lawson AB, Browne WJ, Rodeiro CL. Disease mapping with WinBUGS and MLwiN. Hoboken: John Wiley; 2003, 45-65.

15. Lawson AB, Biggeri AB, Boehning D, Lesaffre E, Viel JF, Clark A, et al. Disease mapping models: an empirical evaluation. Stat 
Med 2000;19(17-18):2217-2241.

16. Dabney AR, Wakefield JC. Issues in the mapping of two diseases. Stat Methods Med Res 2005;14(1):83-112.

17. Held L, Natário I, Fenton SE, Rue H, Becker N. Towards joint disease mapping. Stat Methods Med Res 2005;14(1):61-82.

18. Asadi-Lari M, Vaez-Mahdavi MR, Faghihzadeh S, Cherghian B, Esteghamati A, Farshad AA, et al. Response-oriented measuring inequalities in Tehran: second round of UrbanHealth Equity Assessment and Response Tool (Urban HEART-2), concepts and framework. Med J Islam Repub Iran 2013;27(4):236-248.

19. Bilancia M, Fedespina A. Geographical clustering of lung cancer in the province of Lecce, Italy: 1992-2001. Int J Health Geogr 2009;8:40.

20. Kelsall JE, Wakefield JC. Discussion of 'Bayesian models for spatially correlated disease and exposure data', by Best et al. Bayesian Stat 1999;6:151.

21. Anselin L. Local indicators of spatial association-LISA. Geogr Anal 1995;27(2):93-115.

22. Matkan AA, Mohaymany A S, Mirbagheri B, Shahri M. Explorative spatial analysis of traffic accidents using GWPR model for urban safety planning; 2011 [cited 2018 Jan 15]. Available from: http://onlinepubs.trb.org/onlinepubs/conferences/2011/RSS/1/Matkan,A.pdf.

23. Boskabadi H, Maamouri G, Mafinejad S, Rezagholizadeh F. Clinical course and prognosis of hemolytic jaundice in neonates in North East of Iran. Maced J Med Sci 2011;4(4):403407.

24. Ramy N, Ghany EA, Alsharany W, Nada A, Darwish RK, Rabie WA, et al. Jaundice, phototherapy and DNA damage in fullterm neonates. J Perinatol 2016;36(2):132-136.

25. Mohsnzadeh A, Javadi T, Yari F, Shahkarami K. Effect barley flour on decrease neonatal jaundice. Lorestan Uni Med Sci 2004;7(2):17-22 (Persian).

26. Eghbalian F, Monsef AR. Comparison of the efficacy and complications between two dimensional phototherapy (cylindrical) and uni dimensional phototherapy (double) in neonatal unconjugated hyperbilirubinemia. J Urmia Univ Med Sci 2010; 20(4):254-260 (Persian).

27. Pashapur N, Aghayar Makuee A, Akhondi A, Golmohammad- loo S. Compose effect phenobarbital ana phototherapy with phototherapy in treatment of non hemolitic hyperbilirubinemia in term neonate. J Urmia Nurs Midwifery Fac 2006;5(2):711 (Persian).

28. Hocken berry MJ, Wilson D, Rodgers CC. Wong's essentials of pediatric nursing. 10th ed. St. Louis: Elsevier; 2016, p.1-16.

29. Karamifar H, Pishva N, Amirhakimi GH. Prevalence of phototherapy-induced hypocalcemia. Iran J Med Sci 2002;27(4): 166-168.

30. Aarts MJ, Lemmens VE, Louwman MW, Kunst AE, Coebergh $J W$. Socioeconomic status and changing inequalities in colorectal cancer? A review of the associations with risk, treatment and outcome. Eur J Cancer 2010;46(15):2681-2695.

31. Kim D, Masyn KE, Kawachi I, Laden F, Colditz GA. Neighborhood socioeconomic status and behavioral pathways to risks of colon and rectal cancer in women. Cancer 2010;116(17): 4187-4196.

32. Doubeni CA, Laiyemo AO, Klabunde CN, Young AC, Field TS, Fletcher RH. Racial and ethnic trends of colorectal cancer screening among Medicare enrollees. Am J Prev Med 2010; 38(2):184-191.

33. Doubeni CA, Laiyemo AO, Reed G, Field TS, Fletcher RH. Socioeconomic and racial patterns of colorectal cancer screening among Medicare enrollees in 2000 to 2005. Cancer Epidemiol Biomarkers Prev 2009;18(8):2170-2175.

34. Aune D, Lau R, Chan DS, Vieira R, Greenwood DC, Kampman E, et al. Dairy products and colorectal cancer risk: a systematic review and meta-analysis of cohort studies. Ann Oncol 2012; 23(1):37-45.

35. Green CJ, de Dauwe P, Boyle T, Tabatabaei SM, Fritschi L, Heyworth JS. Tea, coffee, and milk consumption and colorectal cancer risk. J Epidemiol 2014;24(2):146-153.

36. Baena R, Salinas P. Diet and colorectal cancer. Maturitas 2015;80(3):258-264.

37. Krieger N. The real ecological fallacy: epidemiology and global climate change. J Epidemiol Community Health 2015; 69(8):803-804.

38. Sedgwick P. Understanding the ecological fallacy. BMJ 2015; 351:h4773. 